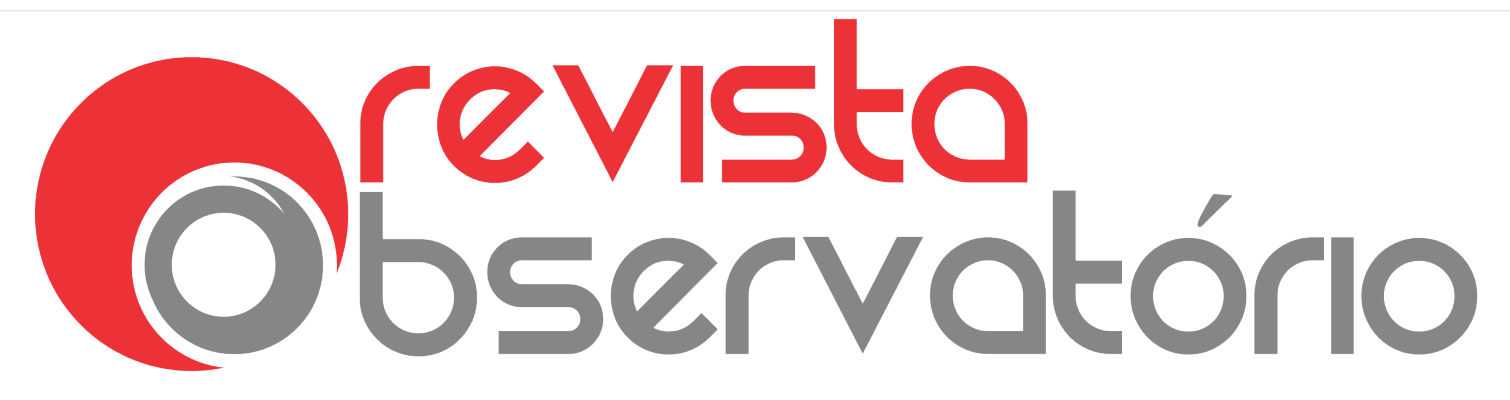

ISSN n² 2447-4266

Vol. 3, n. 1, Janeiro-Março. 2017

DOI: http://dx.doi.org/10.20873/uft.2447-4266.2017v3n1p24

\title{
MULHERES E MÍDIA: \\ caminhos para a Democracia Igualitária
}

"La democracia exige del Estado no sólo velar por la distribuición equitativa de la riqueza sino procurar un distribución equitativa de la palabra. "

Lilián Celiberti

A Revista Observatório inicia seu terceiro ano com diversas mudanças. A mais importante e que tem impacto nos processos editoriais é a mudança de periodicidade. Visando se ajustar as práticas editoriais internacionais a revista passa a ser trimestral. Porém, a Revista Observatório ainda manterá seus dois números extras, sempre que novas temáticas e possibilidades de publicação permitir disponibilizar ao leitor um conjunto de artigos de qualidade. Além disso, iniciamos 2017 em um novo ambiente, com uma versão mais atual e que permite a integração com tecnologias de preservação de longa duração.

Nesse sentido, durante os primeiros meses de 2017, nos debruçamos para a consolidação desses espaços de preservação no Dataverse da Revista Observatório mantido junto a Universidade de Harvard (Estados Unidos), no OpenDepot.org / Edina na University of Edinburgh (Reino Unido), no Social Science Open Access Repository (SSOAR) mantido pela iniciativa GESIS do Leibniz-Institut für Sozialwissenschaften (Alemanha) e em HAL Sciences de l'Homme et de la Société (França). Uma recente inclusão para preservação foi na iniciativa The Internet Archive (Estados Unidos), que além da preservação de longa duração dos arquivos dos textos, permitiu também a disponibilização em novos formatos de leitura (KINDLE, EPUB, DAISY, ABBYY GZ, PDF, FULL TEXT, SINGLE PAGE PROCESSED JP2 e TORRENT). 


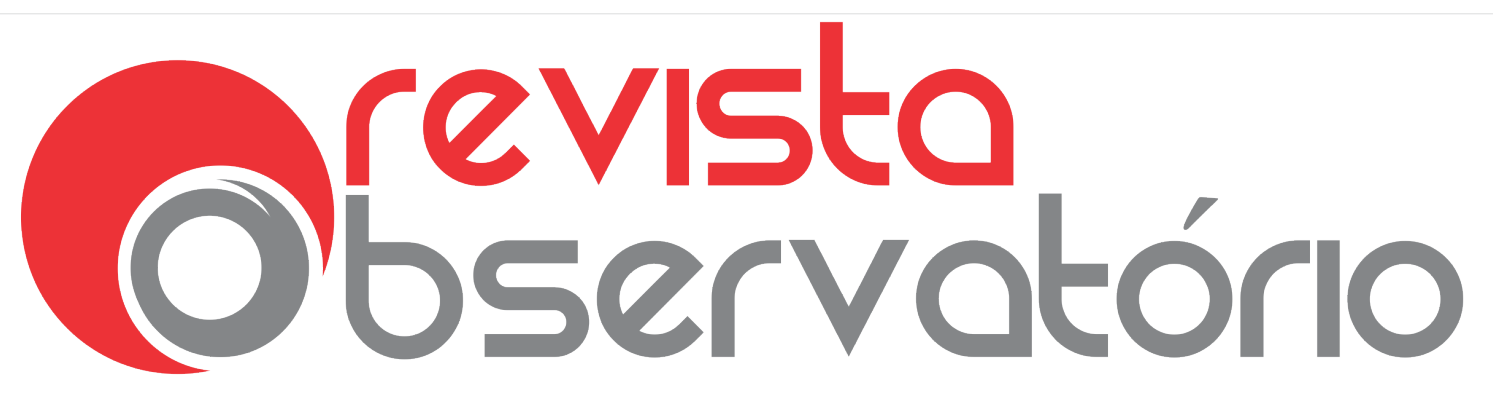

ISSN n² 2447-4266

Vol. 3, n. 1, Janeiro-Março. 2017

DOI: http://dx.doi.org/10.20873/uft.2447-4266.2017v3n1p24

Com o foco na inovação e consolidação, iniciamos nossos dossiês temáticos com uma temática instigante: Mulher e Mídia. As mídias informacionais e publicitárias - cinema, televisão, rádio, internet, jornais, revistas, livros, panfletos, cartazes, outdoors - contribuem para a formação da opinião pública. Se tais mídias, inseridas no processo de produção da informação e da propaganda, reforçam estereótipos e (más) representações sociais, intensificam a desigualdade e o desequilíbrio entre os gêneros (inclusive, para além do binarismo patriarcal) e evidenciam formas de sexismo, preconceitos e discriminações. Assim, não exercem a responsabilidade social, que é formar cidadãs e cidadãos conscientes e críticos.

É de fundamental importância que os meios de Comunicação Social sejam instrumentos para a propagação e a perpetuação da igualdade entre gêneros, principalmente, para a mudança das atuais representações imagéticas das mulheres. Tais mudanças de paradigmas visam a construção de nações inseridas na vanguarda das sociedades desenvolvidas, que respeitam a dignidade e valorizam a pessoa humana.

O dossiê Mulher e Mídia organizado por Cynthia Mara Miranda e Sandra Machado, nesse sentido, acolheu artigos sobre as representações das mulheres nas mídias, em seus vários produtos, com destaque para as relações de gênero que são construídas e desconstruídas nos meios de comunicação de massa; a desigualdade de poder e a invisibilidade das mulheres nos cargos de poder da indústria midiática. É prioridade a atuação dos movimentos de mulheres, feministas, para a construção da igualdade de gênero nos meios de comunicação, bem como a construção de ferramentas para o controle social dos mass media.

O dossiê Mulher e Mídia reúne oito artigos que não apenas atualizam as discussões sobre a representação da imagem das mulheres na política, no cinema, nas revistas e na publicidade como também evidenciam a necessidade de repensar tais representações imagéticas para romper padrões de representação que são construídos hegemonicamente e que homogeneízam as diversidades. $O$ dossiê aponta para necessidade de criar novos 


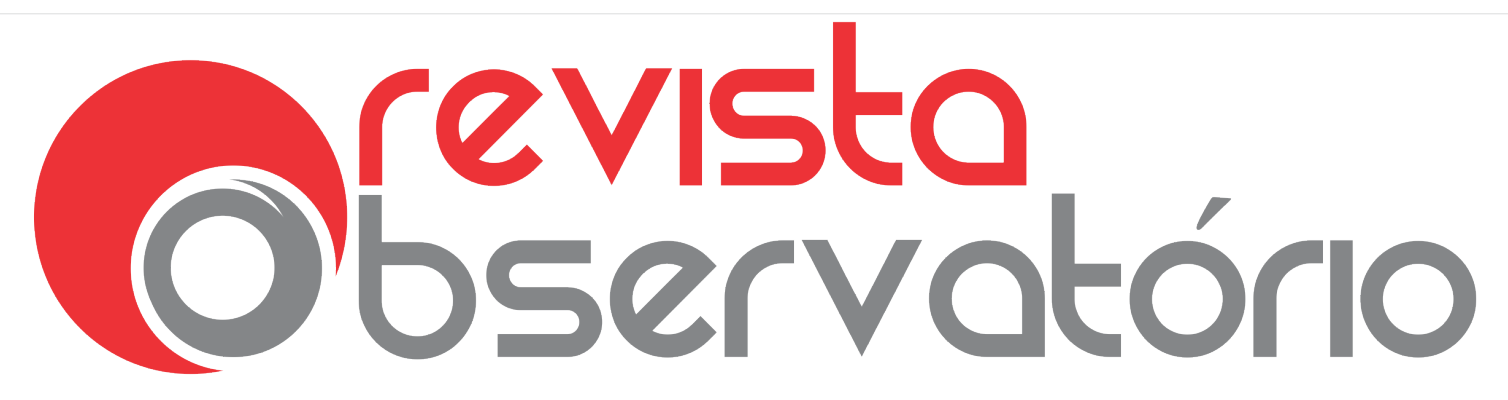

ISSN n² 2447-4266

Vol. 3, n. 1, Janeiro-Março. 2017

DOI: http://dx.doi.org/10.20873/uft.2447-4266.2017v3n1p24

modelos de representação da imagem das mulheres sustentados por uma perspectiva da igualdade entre os gêneros.

E são esses questionamentos, provocações, movimentos das mulheres nos meios de comunicação que animam os textos desta edição da Revista. O DOSSIÊ abre com o artigo COMUNICAÇÃO E GÊNERO: reflexões sobre as ações da Defensoría Del Público de Servicios de Comunicación Audiovisual da Argentina de Cynthia Mara Miranda e Rose Dayanne Santana Nogueira, que nos propõe uma reflexão sobre a experiência da Argentina em ações de comunicação e gênero no âmbito da Defensoría del Público de Servicios de Comunicación Audiovisual, criada em 2012, como um desdobramento da aplicação da Ley n 26.522 de Servicios de Comunicación Audiovisual, conhecida popularmente como Ley de Medios, sancionada em 2009.

Em AS DUAS FACES DO SEXISMO NA MÍDIA: como Marcela Temer e Dilma Rousseff (PT) são retratadas pela Veja e Istoé, as autoras Ana Maria Conceição Veloso, Fabíola Mendonça de Vasconcelos e Laís Ferreira debatem a forma como a mídia brasileira representa as mulheres no campo político, a partir da análise de reportagens de duas revistas semanais, a Veja e a Istoé. Enquanto a primeira tenta mostrar uma (então candidata a) primeira-dama, Marcela Temer, como "bela, recatada e do lar", a segunda traz a então presidenta da República, Dilma Rousseff, como sendo histérica, destemperada, e sem traquejo político. A manchete de capa é "As explosões nervosas da presidente".

Já O artigo INSTAGRAM E A DESQUALIFICAÇÃO DO FEMININO NAS ELEIÇÕES PRESIDENCIAIS BRASILEIRAS EM 2014, de Luciana Panke e Alice Lima analisa a desqualificação do feminino nas eleições, ao tomar como objeto de pesquisa os comentários contra a presidenta Dilma Rousseff (PT), durante o segundo turno da campanha presidencial em 2014. Tais comentários depreciativos foram publicados no perfil oficial da então presidenta no Instagram.

No artigo QUANDO TODAS AS CORES DOS CINEMAS SÃO O AZUL, A COR MAIS FRIA: Uma Análise Sobre Produções Audiovisuais e Gênero, a autora Sandra Machado 


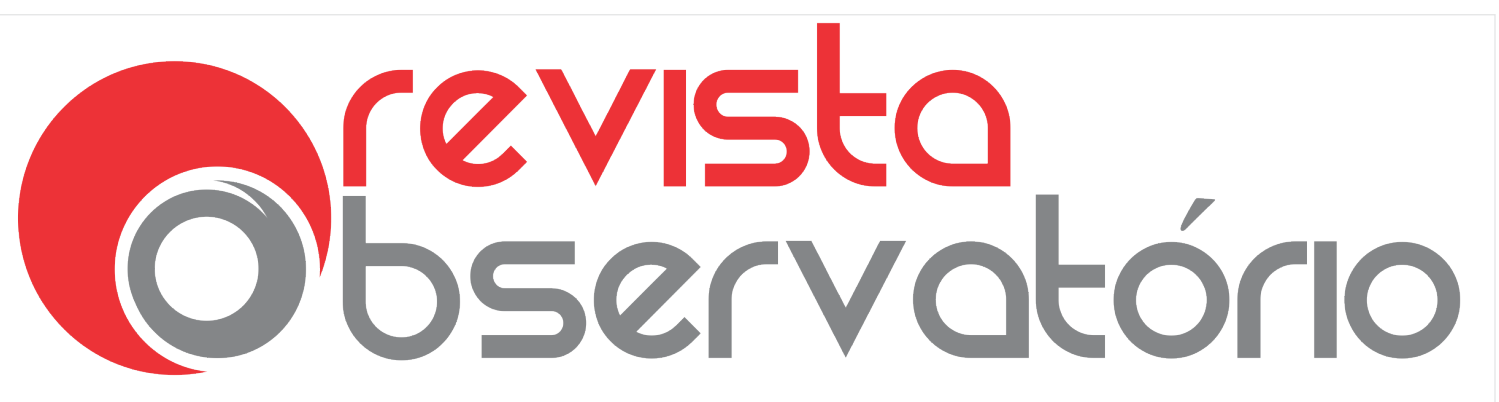

ISSN n² 2447-4266

Vol. 3, n. 1, Janeiro-Março. 2017

DOI: http://dx.doi.org/10.20873/uft.2447-4266.2017v3n1p24

analisa, por meio de estatísticas e também com a crítica do filme Azul é a Cor Mais Quente (França, 2013), as características fundamentais nas produções audiovisuais eurocêntricas hegemônicas e dominantes no panorama mundial - que instigam, perpetram, e perpetuam a anulação e/ou a negação do feminino, das mulheres, nos cinemas, tanto enquanto personagens como no desempenho das funções de produção, direção, edição, roteiros ou cinegrafia.

Em DE PERNAS PRO AR: A Revolution Confined to the Bedroom, a autora Roberta Gregoli apresenta uma reflexão sobre os elementos cinemáticos de uma Globochanchada imensamente popular, De Pernas para o Ar (Roberto Santucci, 2011), à luz das teorias feministas e ainda do teórico da linguagem Mikhail Bakhtin acerca do carnavalesco. $\mathrm{O}$ artigo investiga o modo pelo qual a crescente demanda por representação popular é usada para cooptar outras que seriam progressistas - incluindo as feministas.

Em seu artigo \#VELHAPRAISSO: a representação da velhice feminina em campanha publicitária da Natura, a autora Denise Castilhos de Araújo reflete sobre a representação social da velhice feminina em um filme publicitário da campanha \#velhapraisso, da marca de cosméticos brasileira Natura, por meio da teoria das representações sociais, a partir das propostas teóricas de Moscovici (1978) e Jodelet (2001).

No artigo CONVENÇÕES CORPORAIS E O MEDO DE ENVELHECER: Ideais de Juventude e Beleza Midiáticos Versus Aceitação Pessoal e Social da Imagem Real, as autoras Mônica Fort, Ivania Skura e Cristina Brisolara questionam o binômio beleza e juventude como padrão estético social e culturalmente construído pela mídia, que alimenta o inconformismo das mulheres com seus corpos e levantam a necessidade de repensar o padrão de representação da mulher velha que é veiculado pela mídia brasileira.

O último artigo do dossiê APROPRIAÇÕES MIDIÁTICAS DO FEMINISMO NEGRO NA CONTEMPORANEIDADE BRASILEIRA, as autoras Telma Sueli Pinto Johnson, Pedro Augusto Farnese de Lima e Marcela Xavier Ribeiro examinam as apropriações baseadas em reflexões teórico-conceituais sobre a problemática da comunicação em sociedades midiatizadas e 


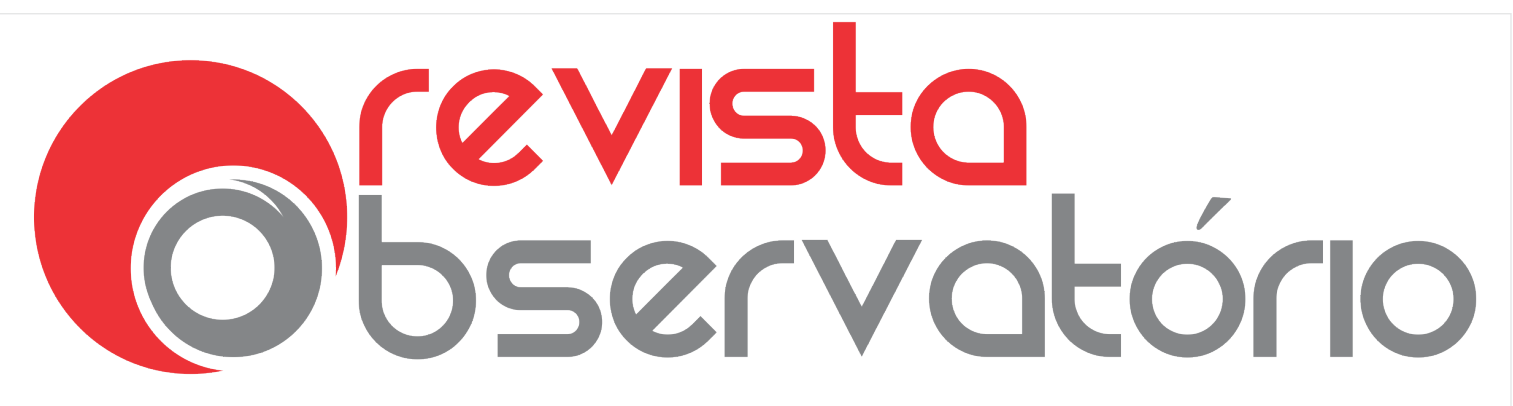

ISSN n² 2447-4266

Vol. 3, n. 1, Janeiro-Março. 2017

DOI: http://dx.doi.org/10.20873/uft.2447-4266.2017v3n1p24

suas relações com as diversidades, tendo como objeto de estudo a página do Instituto da Mulher Negra Geledés, no Facebook, com o propósito de identificar modalidades de interações entre seus/suas visitantes.

A heterogeneidade de temas dialoga, no presente dossiê, com diferentes abordagens teórico-metodológicas e a defesa de uma comunicação para a igualdade é o que unifica a abordagem dos artigos. Os textos apresentados colaboram para tecer linhas de reflexão que revelam esforços coletivos de mulheres na academia e nos movimentos sociais para avançar na efetivação do direito à comunicação e da igualdade de gênero.

Na seção de ARTIGOS LIVRES, iniciamos com o artigo A REPRESENTAÇÃO DAS MULHERES EM FOTOS JORNALÍSTICAS DE FAVELAS DO RIO DE JANEIRO, de Janaina Dias Barcelos. A autora trabalha com 302 imagens de favelas do Rio de Janeiro, publicadas nos meses de setembro, outubro e novembro dos anos 2010, 2012 e 2014, onde faz um recorte com fotos que retratam mulheres adultas como protagonistas. $O$ objetivo foi verificar qual a representação social das mulheres situadas no espaço favela e quais imaginários sociodiscursivos esse modo de apresentá-las poderia engendrar, se reforçaria estereótipos negativos cristalizados ou se daria a ver alguma complexidade e diversidade.

No artigo JORNALISMO E DISCURSO: as representações sobre o leitor nas páginas de O Conciliador do Maranhão (1821-1823), Roseane Arcanjo Pinheiro e Antonio Hohlfeldt analisar o discurso do jornal O Conciliador do Maranhã, o sobre as intenções e a identidade do leitor da publicação através da seção "Correspondência". O jornal foi marco da constituição do campo jornalístico na cidade de São Luís em uma conjuntura de alianças locais e acomodação política frente às mudanças no regime absolutista português.

Em RECEITANDO FICÇÕES PARA AFLIÇÕES: a Farmácia Literária X Como Proust pode mudar sua vida, leda Tucherman trata do estudo dos vínculos e dos afetos na subjetividade contemporânea. A autora analisa a cultura somática que começou a se desenvolver desde os anos 80 , correlata de uma compreensão neuroquímica da subjetividade, que atua 


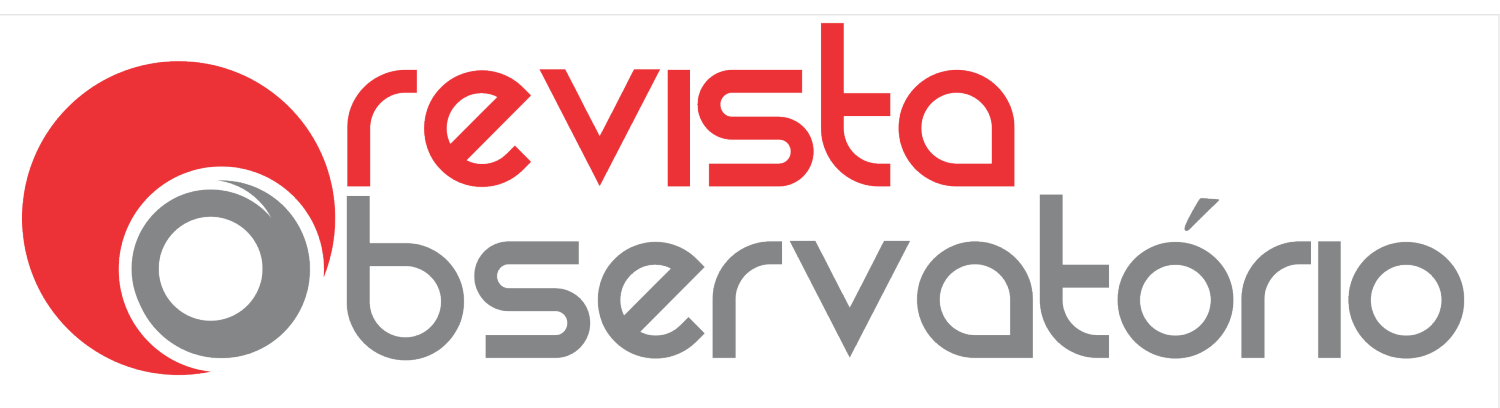

ISSN n² 2447-4266

Vol. 3, n. 1, Janeiro-Março. 2017

DOI: http://dx.doi.org/10.20873/uft.2447-4266.2017v3n1p24

reforçando um narcisismo pragmático e nos afasta do regime que alimentou nossos sistemas imaginários e simbólicos: a literatura.

No artigo PRECONCEITO LINGUÍSTICO: Origem na Sociedade; Término na Escola, Maridelma Laperuta-Martins apresenta o desenvolvimento e resultado de uma pesquisa que relacionou o preconceito linguístico à educação. Partindo da Teoria Sociolinguística e com a pedagogia freireana (FREIRE, 1980) a autora realizou discussões com professores e alunos da educação básica sobre conceitos da variação e preconceito linguístico.

Já no artigo TENSÕES ENTRE O REGISTRO E A ENCENAÇÃO: a imagem de Aylan Kurdi e sua constituição em totem, Ana Paula da Rosa Tendo apresenta o caso das fotografias de Aylan Kurdi como objeto empírico, questionando como a imagem se consolida em totem a partir de sua inscrição na circulação e se há uma força espectral nas imagens que resultam em sua permanência. Para a reflexão, a autora utilizou os conceitos de fagia social e midiática (ROSA, 2016), autorreferencialidade (BAITELLO JR, 2005), além dos aportes específicos da midiatização com Verón, Fausto Neto, Braga e Ferreira dentre outros.

No artigo UM RESGATE DO JORNALISMO: do surgimento à imersão, Sheila Borges de Oliveira e Diego Gouveia Moreira partem da questão "como se reconfigurar para continuar a ser reconhecido como o campo de construção do real, dando sentido ao emaranhado de informações que circulam no mundo virtual?". O artigo se propõe a discutir o futuro do jornalismo em tempos de convergência tecnológica.

Heitor Costa Lima da Rocha e Ivo Henrique França de Andrade Dantas Cavalcanti apresentam o artigo WEBJORNALISMO: Dos Portais Às Redes Sociais. Nele, os autores apresentam a internet como um espaço de trocas simbólicas em que a lógica da comunicação massiva passa por um processo de transformação para um modelo de autocomunicação em massa, focando na gama de novas possibilidades para a participação do leitor e disseminação da notícia. 


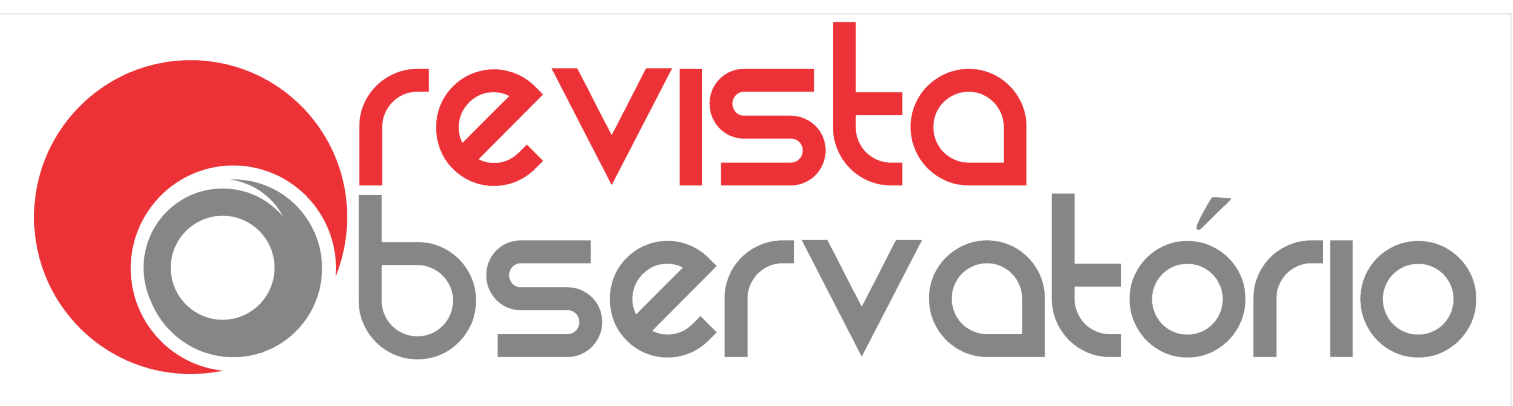

ISSN n² 2447-4266

Vol. 3, n. 1, Janeiro-Março. 2017

DOI: http://dx.doi.org/10.20873/uft.2447-4266.2017v3n1p24

Em OS RECADOS DAS ELEIÇÕES MUNICIPAIS DE 2016: manutenção do status quo ou mudança?, Adriano Oliveira analisa cinco eleições municipais para discutir o porquê dos eleitores estão decepcionados com os políticos e de que existe onda conservadora no Brasil. Para isso utiliza quadro indicadores: (1) Percentuais da abstenção eleitoral e votos brancos e nulos; (2) Quantidade de prefeituras conquistadas pelos partidos políticos; (3) Número de competidores; (4) E taxa de penetração eleitoral por parte das agremiações partidárias.

No artigo PUBLICIDADE GOVERNAMENTAL DE UTILIDADE PÚBLICA EM SAÚDE: considerações sobre a dimensão organizacional no circuito das práticas de produção no Ministério da Saúde, Marcelo Rodrigo de Avelar Bastos Alves e Janine Miranda Cardoso focam na saúde como um complexo conceitual com atores, práticas, contextos e dinâmicas particulares. Discutem a articulação e tensionamento entre o disposto nas normas e o atualizado nas práticas cotidianas inseridas no contexto social, além de resultado de negociações e disputas entre atores e organizações envolvidas na publicidade governamental em Saúde.

Em LIBERDADE DE IMPRENSA SOB AMEAÇA: uma análise dos casos de violência contra jornalistas no Tocantins, Gabriela Pereira Melo e Francisco Gilson Rebouças Porto Junior discutem os casos de violência contra jornalistas no Tocantins. Esta pesquisa ilustra casos acometidos contra jornalistas do estado no exercício da profissão, impedidos de desenvolverem seu trabalho por meio de violência entre os anos de 2012 e 2016.

No artigo NOTÍCIAS NO PULSO: Uma análise de aplicativos jornalísticos em relógios inteligentes, Maíra Evangelista de Sousa descreve e analisa aplicativos jornalísticos disponíveis em relógios inteligentes. O estudo foi realizado a partir da observação dos aplicativos BBC News e Le Monde, durante o mês de maio de 2016, em um smartwatch Moto 360.

Para finalizar, na seção ENTREVISTAS, apresentamos uma conversa intitulada DEMOCRACIA FEMINISTA CONTRA O FASCISMO: Entrevista com a filósofa Marcia Tiburi, de 


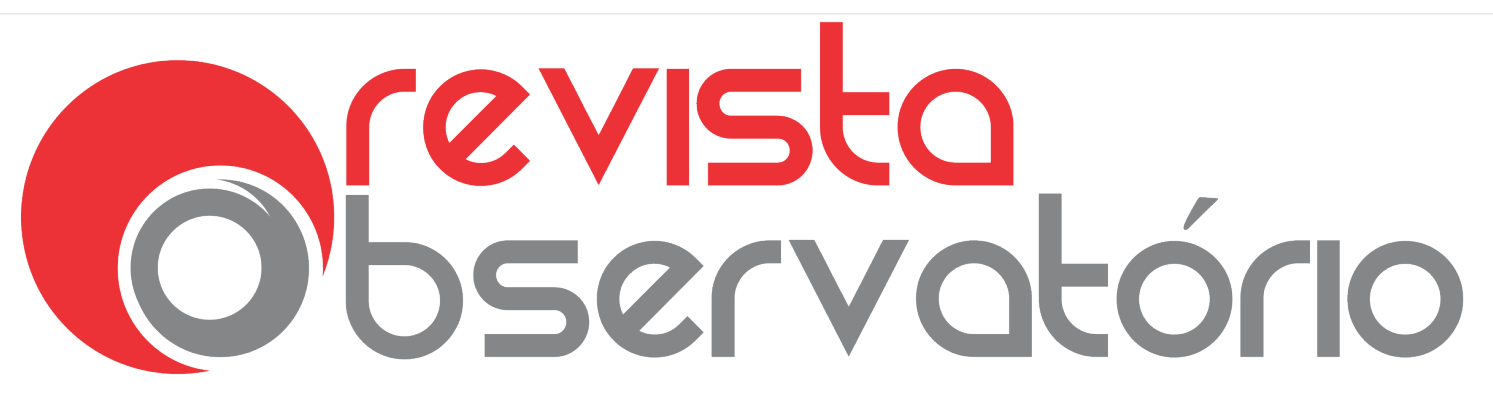

ISSN n² 2447-4266

Vol. 3, n. 1, Janeiro-Março. 2017

DOI: http://dx.doi.org/10.20873/uft.2447-4266.2017v3n1p24

Sandra de Souza Machado. Nessa entrevista, exemplo da atuação de mulheres feministas engajadas na reconstrução política democrática no Brasil. Márcia Tiburi. Ela idealizadora e uma das fundadoras do movimento político PartidA, que ainda está em formação, mas já se espalha por todo o país. Nascido em maio de 2015, o movimento tomou corpo nas redes sociais e conta com mulheres que atuam em todas as áreas e pertencem às diversas classes sociais, etnias, gerações e orientações sexuais - tanto no mundo digital como em reuniões presenciais nas principais cidades e capitais. Nos preceitos da PartidA, há a necessidade de políticas praticadas e idealizadas de forma horizontal, a partir das comunidades, até que consiga eleger futuras representantes, como deputadas federais e estaduais, senadoras, vereadoras ou prefeitas.

Com efeito, sejam todos bem-vindos as discussões e provocações de nosso primeiro número de 2017.

Palmas-TO/Brasília-DF, março de 2017

Editores Convidados / Associate Editors / Editores Asociados

Cynthia Mara Miranda, Universidade Federal do Tocantins, Programa de Pós-Graduação em Comunicação e Sociedade (PPGCOM-UFT), Brasil.

Sandra de Souza Machado, Universidade de Brasília, Brasil.

Editor Geral / Chief Editor / Editor general Francisco Gilson Rebouças Porto Junior, Universidade Federal do Tocantins (UFT), Programa de Pós-Graduação em Comunicação e Sociedade (PPGCOM-UFT), Brasil.

\section{Referências}

ALVES, M. R. DE A. B.; CARDOSO, J. M. PUBLICIDADE GOVERNAMENTAL DE UTILIDADE PÚBLICA EM SAÚDE: considerações sobre a dimensão organizacional no circuito das práticas de produção no Ministério da Saúde. Revista Observatório, v. 3, n. 1, p. 415-433, 30 mar. 2017.

BARCELOS, J. D. A REPRESENTAÇÃO DAS MULHERES EM FOTOS JORNALÍSTICAS DE FAVELAS DO RIO DE JANEIRO. Revista Observatório, v. 3, n. 1, p. 233-257, 30 mar. 2017.

CASTILHOS DE ARAUJO, D. \#VELHAPRAISSO: a representação da velhice feminina em campanha publicitária de natura. Revista Observatório , v. 3, n. 1, p. 161-182, 30 mar. 2017.

DA ROSA, A. P. TENSÕES ENTRE O REGISTRO E A ENCENAÇÃO: a imagem de Aylan Kurdi e sua constituição em totem. Revista Observatório , v. 3, n. 1, p. 327-351, 30 mar. 2017. 


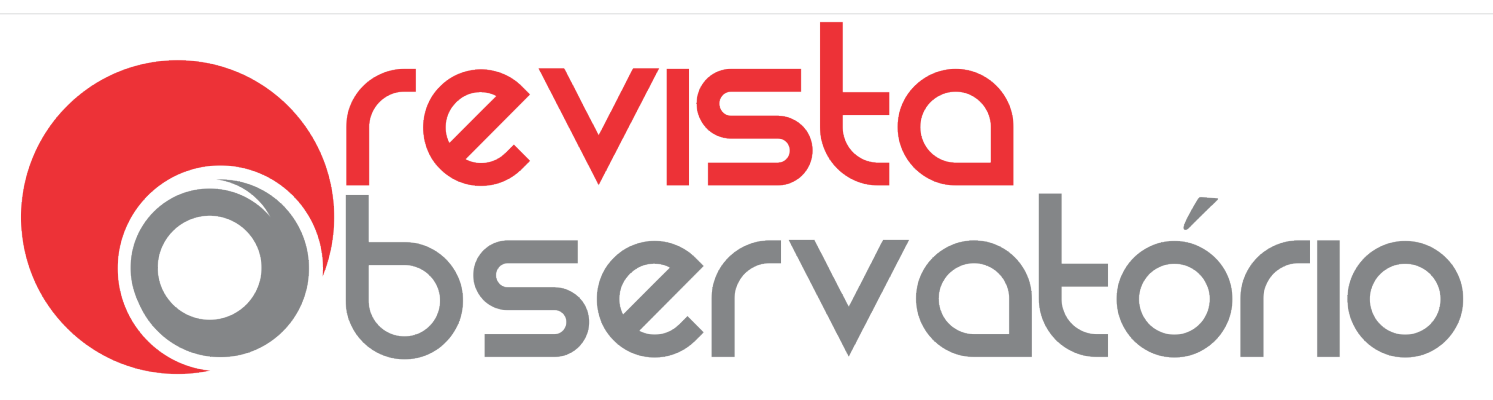

ISSN n² 2447-4266

Vol. 3, n. 1, Janeiro-Março. 2017

DOI: http://dx.doi.org/10.20873/uft.2447-4266.2017v3n1p24

FORT, M. C.; SKURA, I.; BRISOLARA, C. CONVENÇÕES CORPORAIS E O MEDO DE ENVELHECER: Ideais de Juventude e Beleza Midiáticos Versus Aceitação Pessoal e Social da Imagem Real. Revista Observatório , v. 3, n. 1, p. 183-204, 30 mar. 2017.

GREGOLI, R. DE PERNAS PRO AR: uma revolução confinada ao quarto. Revista Observatório, v. 3, n. 1, p. 131-160, 30 mar. 2017

JOHNSON, T. S. P.; FARNESE, P. A.; RIBEIRO, M. X. APROPRIAÇÕES MIDIÁTICAS DO FEMINISMO NEGRO NA CONTEMPORANEIDADE BRASILEIRA. Revista Observatório , v. 3, n. 1, p. 205-232, 30 mar. 2017.

LAPERUTA-MARTINS, M. PRECONCEITO LINGUÍSTICO: Origem na Sociedade; Término na Escola. Revista Observatório , v. 3, n. 1, p. 305-326, 30 mar. 2017.

MACHADO, S. DE S. DEMOCRACIA FEMINISTA CONTRA O FASCISMO: Entrevista com a filósofa Marcia Tiburi. Revista Observatório, v. 3, n. 1, p. 480-491, 30 mar. 2017.

MACHADO, S. DE S. QUANDO TODAS AS CORES DOS CINEMAS SÃO O AZUL, A COR MAIS FRIA: Uma Análise Sobre Produções Audiovisuais e Gênero. Revista Observatório , v. 3, n. 1, p. 105-130, 30 mar. 2017.

MELO, G. P.; PORTO JUNIOR, F. G. R. LIBERDADE DE IMPRENSA SOB AMEAÇA: uma análise dos casos de violência contra jornalistas no Tocantins. Revista Observatório, v. 3, n. 1, p. 434-456, 30 mar. 2017.

MIRANDA, C. M.; NOGUEIRA, R. D. S. COMUNICAÇÃO E GÊNERO: reflexões sobre as ações da Defensoría Del Público de Servicios de Comunicación Audiovisual da Argentina. Revista Observatório , v. 3, n. 1, p. 33-57, 30 mar. 2017.

OLIVEIRA, A. OS RECADOS DAS ELEIÇÕES MUNICIPAIS DE 2016: manutenção do status quo ou mudança?. Revista Observatório , v. 3, n. 1, p. 396-414, 30 mar. 2017.

OLIVEIRA, S. B. DE; MOREIRA, D. G. UM RESGATE DO JORNALISMO: do surgimento à imersão. Revista Observatório , v. 3, n. 1, p. 352-373, 30 mar. 2017.

PANKE, L.; LIMA, A. INSTAGRAM E A DESQUALIFICAÇÃO DO FEMININO NAS ELEIÇÕES PRESIDENCIAIS BRASILEIRAS EM 2014. Revista Observatório , v. 3, n. 1, p. 84-104, 30 mar. 2017.

PINHEIRO, R. A.; HOHLFELDT, A. JORNALISMO E DISCURSO: as representações sobre o leitor nas páginas de $O$ Conciliador do Maranhão (1821-1823). Revista Observatório, v. 3, n. 1, p. 258-279, 30 mar. 2017.

ROCHA, H. C. L. DA; CAVALCANTI, I. H. F. DE A. D. WEBJORNALISMO: Dos Portais Às Redes Sociais. Revista Observatório , v. 3, n. 1, p. 374-395, 30 mar. 2017.

SOUSA, M. E. DE. NOTÍCIAS NO PULSO: Uma análise de aplicativos jornalísticos em relógios inteligentes. Revista Observatório, v. 3, n. 1, p. 457-479, 30 mar. 2017.

TUCHERMAN, I. RECEITANDO FICÇÕES PARA AFLIÇÕES: a Farmácia Literária X Como Proust pode mudar sua vida. Revista Observatório, v. 3, n. 1, p. 280-304, 30 mar. 2017.

VELOSO, A. M. C.; VASCONCELOS, F. M. DE; FERREIRA, L. AS DUAS FACES DO SEXISMO NA MÍDIA: como Marcela Temer e Dilma Rousseff (PT) são retratadas pela Veja e IstoÉ. Revista Observatório, v. 3, n. 1, p. 58-83, 30 mar. 2017. 